\title{
Occupational Exposure to Particulate Matter from Biomass Smoke and Its Relationship to Respiratory Symptoms and Pulmonary Function among Rural Women Involved in Cassava Processing in Nigeria
}

\author{
Tochi J. Okwor ${ }^{*}$, Obianuju B. Ozoh², Ifeoma J. Okonkwo ${ }^{3}$, Akin Osibogun ${ }^{1}$ \\ ${ }^{1}$ Centre for Epidemiology and Health Development, Ibeju Lekki, Nigeria \\ ${ }^{2}$ College of Medicine University of Lagos, Idi Araba, Nigeria \\ ${ }^{3}$ University of Nigeria Teaching Hospital, Ituku-Ozalla, Nigeria \\ Email: *okwortochi@yahoo.com
}

How to cite this paper: Okwor, T.J., Ozoh, O.B., Okonkwo, I.J. and Osibogun, A. (2017) Occupational Exposure to Particulate Matter from Biomass Smoke and Its Relationship to Respiratory Symptoms and Pulmonary Function among Rural Women Involved in Cassava Processing in Nigeria. Open Journal of Preventive Medicine, 7, 41-54.

https://doi.org/10.4236/ojpm.2017.73004

Received: February 9, 2017

Accepted: March 21, 2017

Published: March 24, 2017

Copyright $\odot 2017$ by authors and Scientific Research Publishing Inc. This work is licensed under the Creative Commons Attribution International License (CC BY 4.0).

http://creativecommons.org/licenses/by/4.0/

\begin{abstract}
Background: Cassava processing is an important source of livelihood for many rural women and involves prolonged exposure to biomass smoke. The impact of this exposure on respiratory health of these women has not been explored. We aimed to compare the frequency of respiratory symptoms and pulmonary function among cassava processing women to that of petty traders as well as the levels of particulate matter $\mathrm{PM}_{2.5}$ and $\mathrm{PM}_{10}$ at the workplaces of these women. Methods: A comparative cross-sectional design. Questionnaire was administered; spirometry was performed; $\mathrm{PM}_{2.5}$ and $\mathrm{PM}_{10}$ were sampled. Descriptive statistics were used and multiple logistic regressions were performed to assess the relationship between predictors and outcome variables. Results: 528 non-smoking women were recruited (264 cassava processors and 264 petty traders). The women were matched by baseline parameters. $\mathrm{PM}_{2.5}$ levels at the cassava processing plants were $\left(50 \pm 10.0 \mu \mathrm{g} / \mathrm{m}^{3}\right)$ while the levels at the petty traders' stalls were $13.0 \pm 10.0 \mu \mathrm{g} / \mathrm{m}^{3}(\mathrm{P}<0.001)$. One-year prevalence of respiratory symptoms among cassava processors compared to petty traders was as follows: cough $22.7 \%$ versus $9.5 \%(\mathrm{P}<0.001)$, chronic bronchitis $5.7 \%$ versus $2.3 \%(\mathrm{P}=0.045)$, phlegm $23.1 \%$ versus $11 \%$, wheezing $10.2 \%$ versus $5.3 \%(\mathrm{P}=0.05)$, breathlessness $36 \%$ versus $30.7 \%(\mathrm{P}=0.230)$. The mean (standard deviation) of Forced Vital Capacity (FVC) of $2.11 \pm 0.37$ liters, Forced Expiratory Volume in one second (FEV1) of $1.58 \pm 0.38$ liters and FEV1/FVC of $74.12 \% \pm 7.55 \%$ among cassava processors was significantly lower than FVC of $2.19 \pm 0.28$ liters, $\mathrm{FEV}_{1}$ of $1.72 \pm 0.26$ liters and FEV1/FVC
\end{abstract}


of $78.34 \% \pm 5.05 \%$ among petty traders $(\mathrm{P}=0.007,<0.001,<0.001$ and $<0.001$ respectively). Prevalence of obstructive pulmonary defect (FEV1/FVC $<70 \%$ ) among the cassava processors was $21.3 \%$ compared to $6.4 \%$ among petty traders $(\mathrm{P}<0.001)$. The factors that predicted an obstructive pulmonary defect were occupational biomass fuel use (OR 6.101, CI 3.212 - 11.590), age group 50 years - 60 years (OR 6.805, CI 1.764 - 26.235) and working as a cassava processor for $\geq 10$ years (OR 14.916, CI 5.077 - 43.820) compared to <10 years. Conclusion: Cassava processors are exposed to very high levels of $\mathrm{PM}_{2.5}$, having more respiratory symptoms, lower pulmonary function parameters and higher frequency of obstructive pulmonary defect compared to women not occupationally exposed to biomass. Use of more efficient fuel in cassava processing and personal protective equipment may limit the harmful health effects of biomass among these vulnerable women.

\section{Keywords}

Biomass, Respiratory Symptoms, Particulate Matter, Pulmonary Function, Obstructive Pulmonary Defect

\section{Introduction}

Cassava processing into garri (a major staple food in Nigeria) is an important source of livelihood for many rural women in Nigeria and involves prolonged exposure to biomass smoke. These women use wood in open fires to roast the cassava in semi-enclosed huts for 8 to 10 hours for up to six days in a week. The use of biomass fuel for cooking is associated with exposures to high levels of $\mathrm{PM}_{2.5}, \mathrm{PM}_{10}$, black carbon, sulphur dioxide etc. which have been associated with several adverse health effects such as upper and lower respiratory tract infections, chronic obstructive pulmonary disease (COPD), asthma, cancer, low birth weight, cataract and blindness [1] [2] [3]. The World Health Organization recommends acceptable levels of $\mathrm{PM}_{2.5}$ and $\mathrm{PM}_{10}$ of $25 \mu \mathrm{g} / \mathrm{m}^{3}$ 24-hour mean and 50 $\mu \mathrm{g} / \mathrm{m}^{3}$ 24-hour mean respectively in households and workplaces, and levels higher than this are usually associated with adverse health effects [4]. The WHO also recommends that workplaces with increased risk of exposures to particulate be assessed to determine if they meet the recommended safety levels [4].

Epidemiological studies on the health effects of biomass smoke have been conducted in a variety of settings and with a variety of study designs. However, in spite of their unquestionable importance, research and information in many aspects of the exposures, risks and health effects of biomass fuel-combustion smoke in occupational settings and the interventions to reduce or avoid it are scarce especially in Nigeria [5]. Most studies on health effects of biomass exposure in developing countries have addressed indoor use in households and the health effects of occupational exposures have not been assessed, in addition to the relationship between exposures to biomass and adverse health effects in semi-enclosed environments such as that in which these women work has not 
been extensively explored.

We designed this study to compare the levels of particulate matter at workplaces, the frequency of respiratory symptoms as well as spirometry parameters between cassava processing women occupationally exposed to biomass smoke and petty traders not occupationally exposed to biomass smoke.

\section{Materials and Methods}

\subsection{Study Design}

The study was a comparative cross-sectional study.

\subsection{Study Area and Study Population}

The study population were workers engaged in the processing of raw cassava into garri using biomass fuel and petty traders in Odogbolu Local Government Area of Ogun state Nigeria. There are small scale garri processing plants located all over Odogbolu Local Government Area of Ogun state in Nigeria that produce the popular "Ijebu garri" and majority of the garri processors are females. Odogbolu Local Government is mainly agrarian engaged in farming, hunting, fishing, lumbering and handicraft. However, some percentage of the population also engage in the service sector and industries [6].

\subsection{Inclusion and Exclusion Criteria}

Females aged between 13 years and 60 years, who had been in the occupation for at least 12 consecutive months prior to the study were included in the study [7] [8] [9]. We excluded those with a previous history of pulmonary tuberculosis, known case of bronchial asthma, obvious skeletal abnormalities of the chest, pregnancy, previous history of work in a dusty environment and past or present history of smoking. Petty traders with a previous occupation involving exposure to biomass smoke were also excluded [10].

\subsection{Sampling}

The sample size was determined using the formula for the comparison of two proportions and a minimum sample size of 264 was calculated for each group with a $5 \%$ precision at $95 \%$ confidence level [11] [12]. A multi-stage sampling technique was used in selecting participants

\subsubsection{Sampling for cassava processors}

Stage 1: Four wards out of the fifteen wards in Odogbolu LGA were selected by a simple random sampling. The selected wards were Odogbolu 1, Odogbolu 2, Okunowa and Aiyepe.

Stage 2: All the workers in all the cassava processing plants were approached for recruitment into the study until the sample size of 264 was achieved.

\subsubsection{Petty traders}

Stage 1, selection of markets: Four of the markets located in the wards where 
the sampled cassava processing plants were selected namely, Okun-Owa, Aiyepe, Odogbolu and Ijebu-Ijesa were selected.

Stage 2, selection of clusters: Following an initial assessment of the markets, all the traders in the markets were grouped into eight clusters based on type of item sold. Out of the list of eight clusters, six clusters were selected by a simple random sampling technique (balloting) these were the clusters that were recruited for the study in each of the markets and these clusters were provision, vegetables, textiles, fruits, food condiments and hardware.

Stage 3, selection of participants: Every petty trader in each of the six clusters that met the eligibility criteria was approached for recruitment into the study until the sample size of 264 was achieved.

\subsection{Sampling for the Particulate Matter Measurement}

Three cassava processing plants were selected from each of the four wards using a simple random sampling (balloting). Then particulate matter sampling was done at all the active stoves "amo" in the selected plants i.e. all the points that had biomass burning in them. Eventually, a total of 37 points were sampled in twelve cassava processing plants.

The four markets in the four wards were sampled. In each market, nine points that were equidistant from each other were identified and particulate matter measurements carried out. A total of 36 points were sampled in four markets [13].

\subsection{Data Collection Tools and Techniques}

The data was collected over a period of five months between the months of June and November 2014.

\subsubsection{Questionnaire}

Trained interviewers administered structured questionnaires on all participants [14] [15]. The questionnaire was adapted from the American Thoracic Society Questionnaire ATS-DLD-78-A [16] [17] [18] and was used to assess socio-demographic variables, the presence of respiratory symptoms (cough, phelgm, wheezing), family medical history, occupational exposure to substances causing respiratory disorders, exposure to indoor sources of pollution, the use of respiratory protection devices and current employment history. The questionnaire was translated into the Yoruba with independent back translation into English. The interviewer administered questionnaire was pre-tested among workers involved in cassava processing in Imodi, a ward that was not involved in the final study. Slight adjustments in flow and sequence of questions were made to accommodate the observations made at pre-test.

\subsubsection{Anthropometric Measurements}

Height and weight were measured using the standard protocols recommended by the International Society for the Advancement of Kinanthropometry: ISAK [19]. 


\subsubsection{Spirometry}

Spirometry was performed using MiniSpir spirometer S/N 003291 between 9 am and $3 \mathrm{pm}$ daily to minimise diurnal variation [20]. The protocol used was theERS/ATS guidelines 2005 for spirometry performance and interpretation and only the tests that met acceptability and repeatabilitycriteria (within $150 \mathrm{ml} 200$ $\mathrm{ml}$ ) were included. Each participant performed a minimum of three and a maximum of eight acceptable and reproducible forced expiratory maneuvers in a seated position after a brief coaching by a trained investigator. The subjects were instructed to empty their bladder before the commencement of the test. A full bladder and stress incontinence may cause under performance [21] [22]. The measured pulmonary function values were compared with the Nigerian reference values derived by Patrick and Femi-Pearse and the percentage of predicted values were derived [23]. The outcomes of spirometry test were classified as follows; Normal-FEV1/FVC $>70 \%$ \& FVC $>80 \%$ of predicted. Obstructive pulmonary defect FEV1/FVC $<70 \% \&$ FEV1 $<80 \%$ of predicted. Restrictive pulmonary pattern FEV1/FVC $>70 \% \&$ FVC $<80 \%$ of predicted and combined pattern FEV1/FVC $<70 \%$ \& FVC $<80 \%$ predicted [10] [14] [24]. Appropriate precaution was taken to prevent cross infection during spirometry by using a disposable mouth piece for each respondent.

\subsubsection{Measurement of Particulate Matter}

The particulate matter measurements were done from the $10^{\text {th }}$ to $12^{\text {th }}$ of November 2014 between the hours of 10am and $3.30 \mathrm{pm}$ each day. The instrument used was Aerocet PM Monitor of model Aerocet-531 and ambient concentrations of $\mathrm{PM}_{2.5}$ and $\mathrm{PM}_{10}$ were measured. [8] The meter was placed at a height of $1.3 \mathrm{~m}$ above the ground. The physical factors known to affect particulate/dust measurement i.e. wind speed, temperature and barometric pressure were also measured simultaneously using Skymaster Pocket Weather Tracker [25].

\subsection{Ethics}

Ethical approval was obtained from the Lagos University Teaching Hospital Health Research Ethics Committee with approval number ADM/DCST/HREC/980. All participants gave verbal and written informed consent.

\subsection{Data Analysis}

Data analysis was done using IBM SPSS Statistics 20. Categorical data were summarized as proportions and percentages while continuous variables were summarized using means ( \pm standard deviation). Chi square and Fishers exact tests were used for comparison of proportions and the Student $t$ test for comparison of means. Multiple logistic regression was done to assess the relationship between predictors and outcome variables. P-value of $<0.05$ was considered statistically significant.

\section{Results}

A total of 528 respondents comprising 264 cassava processors and 264 petty 
traders participated in the study. Out of this number, 258 (97.7\%) cassava processors and 249 (94.3\%) petty traders had spirometry done. A total of 37 cassava processing points and 36 points in the markets were sampled for particulate matter.

A comparison of the socio-demographic characteristics of the respondents Table 1 showed that the highest proportion of respondents in both groups was within the age group 30 - 39 years, $50.4 \%$ of cassava processors and $56.8 \%$ of petty traders. Amongst the cassava processors, a higher proportion $31.1 \%$ was from Igede ethnic group, followed by Yoruba $26.5 \%$ while most $81.8 \%$ of the petty traders were Yoruba. Amongst the cassava processors, the highest proportion $46.8 \%$ had primary education and $23.2 \%$ had secondary education compared to $55.9 \%$ of petty traders with secondary education and $28.4 \%$ with primary education.

The mean PM concentrations at cassava processing workplaces were higher than those measured at the petty traders' work areas. $\mathrm{PM}_{2.5}$ at the cassava processors workplaces was $50.0 \pm 10.0 \mu \mathrm{g} / \mathrm{m}^{3}$ compared to $13.0 \pm 10.0 \mu \mathrm{g} / \mathrm{m}^{3}$ for

Table 1. Comparison of socio-demographic characteristics of cassava processors and petty traders.

\begin{tabular}{|c|c|c|c|c|}
\hline Parameters & $\begin{array}{c}\text { Cassava processors } \\
\mathrm{n}=264\end{array}$ & $\begin{array}{l}\text { Petty traders } \\
\mathrm{n}=264\end{array}$ & $x^{2}$ & $P$ value \\
\hline \multicolumn{5}{|l|}{ Age (years) } \\
\hline Below 30 & $71(26.9)$ & $74(28.0)$ & 5.083 & 0.079 \\
\hline $30-49$ & $133(50.4)$ & $150(56.8)$ & & \\
\hline $50-60$ & $60(22.7)$ & $40(15.2)$ & & \\
\hline Mean age & $37.39 \pm 12.06$ & $37.83 \pm 10.53$ & $\mathrm{t}=-0.450$ & 0.653 \\
\hline \multicolumn{5}{|l|}{ Ethnicity } \\
\hline Yoruba & $70(26.5)$ & $225(85.2)$ & $197.262^{\star *}$ & $<0.001^{*}$ \\
\hline Igede & $82(31.1)$ & $4(1.5)$ & & \\
\hline Igbo & $44(16.7)$ & $22(8.3)$ & & \\
\hline Isoko/Urhobo & $35(13.3)$ & $5(1.9)$ & & \\
\hline Others & $33(12.5)$ & $8(3.0)$ & & \\
\hline \multicolumn{5}{|l|}{ Level of education } \\
\hline No formal education & $75(28.5)$ & $12(4.6)$ & $111.839^{* *}$ & $<0.001^{\star}$ \\
\hline Primary education & $124(46.8)$ & $77(28.4)$ & & \\
\hline Secondary & $61(23.2)$ & $148(55.9)$ & & \\
\hline Post-secondary & $4(1.5)$ & $27(10.0)$ & & \\
\hline \multicolumn{5}{|l|}{ Monthly income $(=\mathrm{N}=)$} \\
\hline$<10,000$ & $177(67)$ & $159(60.2)$ & 4.732 & 0.096 \\
\hline $10,000-20,000$ & $70(26.5)$ & $75(28.4)$ & & \\
\hline$>20,000$ & $17(6.4)$ & $30(11.4)$ & & \\
\hline Mean income (=N=) & $7075.00 \pm 5665.91$ & $9251.89 \pm 8885.73$ & $\mathrm{~T}=3.356$ & $0.001^{*}$ \\
\hline
\end{tabular}

${ }^{\star} \mathrm{P}<0.05=$ statistically significant; ${ }^{*}$ Fisher's exact test. 
petty traders. $\mathrm{PM}_{10}$ at the cassava processing workplaces was $440.0 \pm 220.0$ $\mu \mathrm{g} / \mathrm{m}^{3}$ compared to $50.0 \pm 10.0 \mu \mathrm{g} / \mathrm{m}^{3}$ for the petty traders and these differences were statistically significant $(\mathrm{P}<0.001)$. The levels at the cassava processing plants were far above the WHO acceptable limit of $25 \mu \mathrm{g} / \mathrm{m}^{3}$ and $50 \mu \mathrm{g} / \mathrm{m}^{3}$ for $\mathrm{PM}_{2.5}$ and $\mathrm{PM}_{10}$ respectively [4].

Table 2 shows that there was a higher occurrence of self reported cough and phlegm among the cassava processors compared to the petty traders. The cassava processors also had lower ventilator function values compared to the petty traders. These differences were statistically significant $(\mathrm{P}<0.05)$.

As shown in Figure 1, One hundred and seventy five representing $68 \%$ of cassava processors compared to 216 (87\%) of petty traders had a normal ventilatory function pattern. A higher proportion 55 (21\%) of cassava processors compared to $16(6 \%)$ of petty traders had an obstrcutive pattern. A higher proportion $18(7 \%)$ of cassava processors compared to $14(6 \%)$ of petty traders had a possibly restrictive pattern. A combined pattern was seen in $10(4 \%)$ of cassava processors compared to $3(1 \%)$ of petty traders. These associations were statistically significant $(\mathrm{P}<0.001)$.

As shown in Table 3, Prevalence of obstructive pulmonary pattern among the cassava processors was $21.3 \%$ compared to $6.4 \%$ in petty traders $(\mathrm{P}<0.001)$. The cassava processors were about six times more likely to have an obstructive ventilatory function abnormality compared to petty traders (OR, 6.101, 95\% CI, 3.212 - 11.590). Respondents in the 50 - 60 years' age group were almost seven times more likely to have an obstructive ventilatory function abnormality

Table 2. Respiratory symptoms and pulmonary function parameters of participants

\begin{tabular}{|c|c|c|c|c|c|}
\hline Symptom & $\begin{array}{c}\text { Cassava processors } \\
\mathrm{n}=264\end{array}$ & $\begin{array}{c}\text { Petty traders } \\
n=264\end{array}$ & $x^{2}$ & df & $P$ value \\
\hline Cough & $60(22.7)$ & $25(9.5)$ & 17.18 & 1 & $<0.001^{\star}$ \\
\hline Phlegm & $61(23.1)$ & $29(11)$ & 13.72 & 1 & $<0.001^{*}$ \\
\hline $\begin{array}{l}\text { Wheezing in } \\
\text { the last one } \\
\text { year }\end{array}$ & $27(10.2)$ & $14(5.3)$ & 4.47 & 1 & $0.05^{*}$ \\
\hline Parameter & $\begin{array}{c}\text { Cassava } \\
\text { processors (Mean } \\
\pm S D) n=258\end{array}$ & $\begin{array}{c}\text { Petty traders } \\
(\text { Mean } \pm S D) \\
n=249\end{array}$ & $t$ & $\mathrm{P}$-value & \\
\hline FVC (liters) & $2.11 \pm 0.37$ & $2.19 \pm 0.28$ & 2.772 & $0.007^{*}$ & \\
\hline FEV1(liters) & $1.58 \pm 0.38$ & $1.72 \pm 0.26$ & 4.557 & $<0.001^{\star}$ & \\
\hline FEV1/FVC\% & $74.12 \pm 7.55$ & $78.34 \pm 5.05$ & 7.375 & $<0.001^{*}$ & \\
\hline $\begin{array}{c}\text { FVC- } \% \text { of } \\
\text { predicted }(\%)^{* *}\end{array}$ & $87.66 \pm 11.05$ & $90.41 \pm 11.11$ & 2.792 & $0.005^{*}$ & \\
\hline $\begin{array}{c}\text { FEV1-\% of } \\
\text { predicted }(\%)^{* *}\end{array}$ & $83.34 \pm 16.61$ & $90.31 \pm 11.11$ & 5.154 & $<0.001^{\star}$ & \\
\hline $\begin{array}{l}\text { FEV1/FVC\%-\% } \\
\text { percentage of } \\
\text { predicted }(\%)^{* *}\end{array}$ & $94.48 \pm 9.87$ & $100.43 \pm 8.80$ & 7.154 & $<0.001^{\star}$ & \\
\hline
\end{tabular}

${ }^{* *}$ Nigerian reference values derived by Patrick and Femi-Pearse. Patrick, J.M., Femi, Pearse D. Reference values for FEV1 and FVC in Nigerian Men and Women: A graphical summary. Nigerian Medical Journal, (1976), 6, 380-385. 


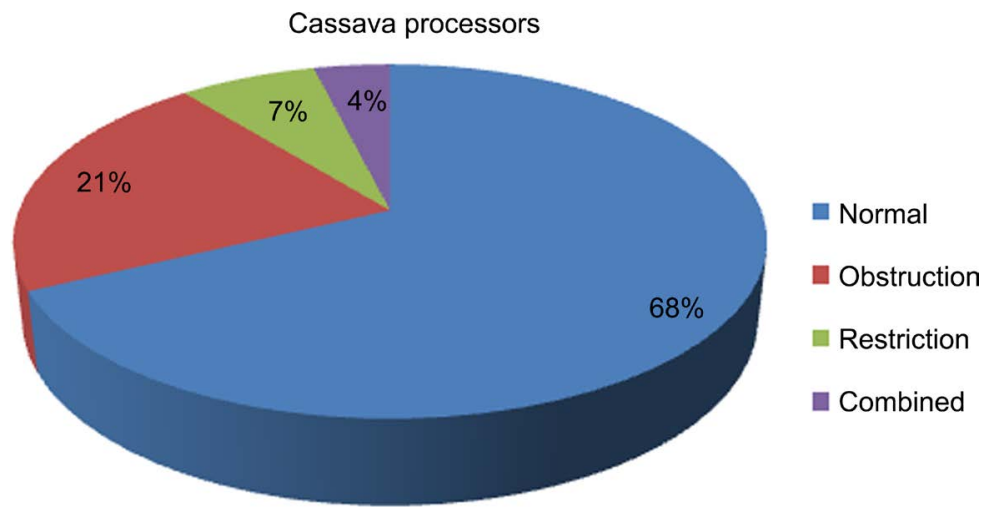

(a)

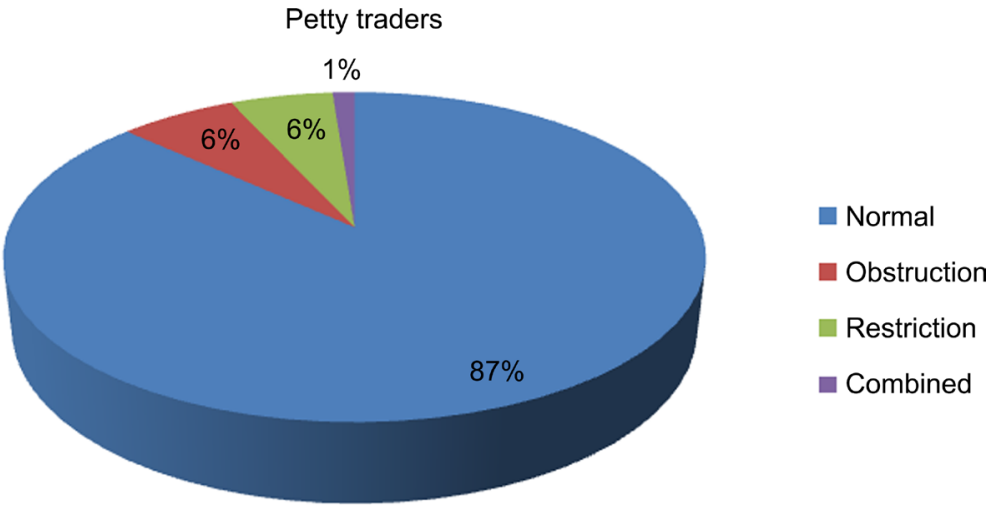

(b)

Figure 1. Comparison of the pulmonaryfunction patterns of cassava processors and petty traders. (a) $\mathrm{n}=258$, (b) $\mathrm{n}=249, \mathrm{P}<0.001$.

Table 3. Logistic regression model for predictors of obstructive ventilatory function among the respondents (cassava processors and petty traders).

\begin{tabular}{ccccc}
\hline Predictor variable & B & OR & CI & P-value \\
\hline Occupation as petty trader & & 1.00 & & \\
Occupation as cassava processor & 1.809 & 6.101 & $3.212-11.590$ & $<0.001^{*}$ \\
Age group $<$ 30 years & & 1.00 & & \\
Age group 30 - 49 years & 1.255 & 3.506 & $0.961-12.797$ & 0.058 \\
Age group 50 - 60 years & 1.917 & 6.805 & $1.764-26.235$ & $0.005^{*}$ \\
$\quad<10$ years in job & & 1.00 & & \\
$\geq 10$ years in job & 2.702 & 14.916 & $5.077-43.820$ & $<0.001^{*}$ \\
\hline
\end{tabular}

${ }^{\star} \mathrm{P}<0.05=$ statistically significant, $\mathrm{OR}=$ Odds ratio, $\mathrm{CI}=(95 \%$ Confidence interval $), \mathrm{B}=$ log odds ratio.

compared to those below 30 years (OR, 6.803, 95\% CI, 1.764 - 26.235). Cassava processors that had been at the job for $\geq 10$ years were almost 15 times more likely to have an obstructive ventilatory function abnormality compared to those in the job for $<10$ years (OR, 14.916, 95\% CI, 5.077 - 43.820).

\section{Discussion}

Ventilatory function is influenced by factors such as age, sex and height [18]. 
The two groups were comparable with respect to the above parameters as majority of respondents were aged 30 - 49 years and there was no significant difference in age and height between the two groups. The two groups were different in terms of ethnicity with majority of cassava processors being of Igede ethnic group while the majority of petty traders were of the Yoruba ethnic group. This distribution of ethnic groups is a reflection of the prevailing socio demographic situation in Odogbolu. Anecdotal evidence indicates that the indigenes of Odogbolu who are of Yoruba ethnic group are land owners who then employ the services of people from other ethnic groups to work in the farms and also perform post harvest processes. The petty traders had higher level of education as evidenced by the higher proportion with secondary and post-secondary education compared to the cassava processors. Cassava processing is mainly an unskilled job so it is not surprising that majority of the cassava processors had only primary education. Respondents were categorized into three income levels [26]. These mean incomes from both occupations were below the Nigerian minimum wage of $=\mathrm{N}=18,000$ [27]. This shows that the cassava processors and the petty traders are both in the low economic class in Nigeria.

The results from this study show that the $\mathrm{PM}_{2.5}, \mathrm{PM}_{10}$ concentrations measured at the cassava processing workplaces exceeded the limits of $\mathrm{PM}_{2.5}$ $\left(0.025 \mathrm{mg} / \mathrm{m}^{3}\right), \mathrm{PM}_{10}\left(0.05 \mathrm{mg} / \mathrm{m}^{3}\right)$ and TSP $\left(0.25 \mathrm{mg} / \mathrm{m}^{3}\right)$ set by WHO [4]. This means that the cassava processors are exposed to $\mathrm{PM}_{2.5}$ level that was twice the WHO limit and $\mathrm{PM}_{10}$ level that was about nine times higher than the set limit [4] [28]. The mean PM value measured at the work areas of the petty traders was below the limits. Given that the metereological parameters known to affect PM distribution were the same at all the locations, it can be inferred that the cassava processors are exposed to PM concentrations that are far higher than that of the petty traders. The implication of this is that while the petty traders work in an atmosphere that is free of harmful PM concentrations, their cassava processing counterparts work long hours in environments with harmful PM concentrations. These particulates are known to cause damaging health effects so they may be the contributory factor to the increased respiratory symptoms and lower ventilatoryfunction indices observed in the cassava processors. In animal models, exposure to toxic particulate matter has been associated with reduced lung compliance and decreased ventilatoryresponse [5]. Particulate matter $\mathrm{PM}_{10}$ and $\mathrm{PM}_{2.5}$ can be inhaled deeply into the lungs. The pathology due to biomass smoke exposure leads to respiratory tract infections, wheezing, chronic bronchitis and COPD [29]. In this study, it was also found that the prevalence of self reported respiratory symptoms which suggest underlying respiratory illness among the cassava processors was higher than that for the petty traders. These findings may be an indication that the particulate matter from exposure to biomass smoke has a damaging effect on the respiratory health of the cassava processors. The significantly higher prevalence of respiratory symptoms observed among the cassava processors exposed to biomass fuel at work was similar to findings in other studies where the differences observed between the symptoms reported by 
respondents in study and control/comparison group were statistically significant $(\mathrm{P}<0.05)$. A study conducted in Ekiti state Nigeria found that women using biomass fuel reported more respiratory symptoms compared to those that did not cook with biomass fuel [9]. Another study conducted among females occupationally exposed to biomass fuel while smoking fish in Oroyokoto village in the Niger Delta region of Nigeria also showed that the exposed women reported more respiratory symptoms compared to their controls [7]. These findings indicate that even in occupational settings, biomass burning seemed to pose a higher risk of respiratory symptoms among exposed compared to the non-exposed.

The result of the ventilatory function tests indicate that all the ventilatory function parameters were lower in the cassava processors compared to the petty traders suggesting significant reductionof lung function in the cassava processors. Obstructive type of impairment was predominant. Like the present finding, several investigators have reported reductionin ventilatoryfunction in women chronically exposed to biomass smoke [8] [30] [31] [32]. The decrease in ventilatory function in the cassava processors who use biomass fuel may be due to chronic inhalation of particulate matter emitted during combustion of biomass leading to inflammatory changes. Some studies have established an association between lower values of lung function, airflow obstruction and chronic exposure to biomass fuel smoke. [8] [33] [34] [35] [36] Researchers in Ekiti state found that all the spirometric parameters evaluated were lower in women using biomass fuel compared to non-biomass fuel users $(\mathrm{P}<0.05)[9]$. Other studies in Nigeria also found a lower lung function parameters among biomass exposed women compared to the unexposed group [37]. Some studies have established an association between lower values of lung function, airflow obstruction and chronic exposure to biomass fuel smoke [2] [34] [38]. These results in the current study and the referenced ones have to be interpreted bearing in mind that it has been shown that exposed workers at baseline tend to have better overall health and pulmonary function than the general population, the so-called healthy worker effect. It is also known that workforce studies are often limited to a "survivor" population because of inability to assess or monitor workers who leave their jobs, thereby underestimating the chronic effects of occupational exposures [39] [40].

In this study, prevalence of obstructive pattern of ventilatory abnormality in cassava processors who burn biomass fuel at work was $21.3 \%$ while in petty traders who do not burn biomass fuel at work, the prevalence of an obstructive abnormality was $6.4 \%$. The factors found to predict development of an obstructive ventilatory abnormality were burning biomass fuel in cassava processing (OR 6.101, CI 3.212 - 11.590), age group 50 years - 60 years (OR 6.805 , CI 1.764 - 26.235) working as a cassava processor for $\geq 10$ years (OR 14.916, CI 5.077 - 43.820). The role of age can be explained by the fact that older people are most likely to have been engaged in the job of cassava processing for longer which also means longer exposure to biomass fuel smoke. 
Respirable particulate matter have been shown to lead to COPD and wood smoke from biomass exposure has been shown to be an independent risk factor for obstructive airways disease and earlier and longer time of exposure has been shown to increase the risk for development of COPD [28] [41]. In a study carried out among rural Guatemalan women, it was found that exposure to biomass smoke was associated with higher gene expression of multiple mediators of airway inflammation and remodelling. These mechanisms could expain some of these observed associations between prolonged biomass exposure and obstructive pattern of ventilatory function abnormality [42].

Our findings that cassava processors who burn biomass were significantly more likely to have respiratory symptoms and have lower respiratory function and obstructive lung abnormality, points to where efforts may be directed and the country may focus additional attention and resources.

Although, personal exposure of respondents to particulate matter was not done in this study it could be reasoned that the higher respiratory symptoms reported by the cassava processors and the lower ventilatory function measured in this group can be attributed to the high PM levels measured in their workplaces. This is in consideration of the fact that they do not use respiratory protective equipment at work and therefore they would inhale almost all PM released by the burning of the biomass fuel.

\section{Conclusion}

Cassava processors are exposed to very high levels of $\mathrm{PM}_{2.5}$ and $\mathrm{P}_{10}$ that are above the WHO standards. They have more respiratory symptoms, lower pulmonary function parameters and higher frequency of obstructive pulmonary defect compared to women not occupationally exposed to biomass. We advocate the use of more efficient fuel in cassava processing as well as the use of personal protective equipment by these vulnerable women to limit the harmful health effects of biomass among them.

\section{Limitations to the Study}

Even though limiting the period to 12 months theoretically reduces errors of recall [43], recall bias may still be unavoidable with self-reported data [44].

\section{References}

[1] Kilabukol, H.J., Matsuki, H. and Nakai, S. (2007) Air Quality and Acute Respiratory Illness in Biomass Exposed Fuel Using Homes in Bagamoyo, Tanzania. International Journal of Environmental Research and Public Health, 4, 39-44. https://doi.org/10.3390/ijerph2007010007

[2] Arora, P., Gupta, R., Chopra, R., Gupta, A., Mishra, N. and Sood, S. (2014) Effect of Chronic Exposure to Biomass Fuel Smoke on Pulmonary Function Test Parameters. International Journal of Research in Medical Sciences, 2, 1488-1494. https://doi.org/10.5455/2320-6012.ijrms20141145

[3] Mishra, V. (2003) Indoor Air Pollution from Biomass Combustion and Acute Respiratory Illness in Preschool Age Children in Zimbabwe. International Journal of 
Epidemiology, 32, 847-853. https://doi.org/10.1093/ije/dyg240

[4] World Health Organization, WHO (2016) Air Quality Guidelines for Particulate Matter, Ozone, Nitrogen Dioxide and Sulfur Dioxide. Global Update 2005 Summary of Risk Assessment.

[5] Torres-Duque, D.M., Perez-Padilla, R., Majid, E. and Giovanni, V. (2008) Biomass Fuels and Respiratory Diseases a Review of the Evidence. American Thoracic Society, 5, 577-590. https://doi.org/10.1513/pats.200707-100RP

[6] Odugbolu-Ogunstatebiz.

[7] Akani, B.A., Dienge, O.P. and Okokon, B.I. (2011) Respiratory Symptoms amongst Females in a Fishing Settlement in the Niger Delta Nigeria. African Journal of Primary Health Care and Family Medicine, 3, 152. https://doi.org/10.4102/phcfm.v3i1.152

[8] Regalado, J., Perez-Padilla, R., Sansores, R., Ramirez, J.I.P., Brauer, M., Pare, P., et al. (2006) The Effects of Biomass Burning on Respiratory Symptoms and Lung Function in Rural Mexican Women. American Journal of Respiratory Critical Care Medicine, 174, 901-905. https://doi.org/10.1164/rccm.200503-479OC

[9] Desalu, O.O., Adekoya, A.O. and Ampitan, B.A. (2010) Increased Risk of Respiratory Symptoms and Chronic Bronchitis in Women Using Biomass Fuels in Nigeria. Journal of Bras Pneumol, 36, 441-446. https://doi.org/10.1590/S1806-37132010000400008

[10] Onyedum, C.C., Chukwuka, J.C., Onwubere, B.J.C., Ulasi, I.I. and Onwukwe, I.O. (2010) Respiratory Symptoms and Pulmonary Function Tests in Nigerians with HIV Infection. African Health Science, 10, 130-137.

[11] Fleis, J.L. (1981) Statistical Methods for Rates and Proportions. John Wiley and Sons, Inc., New York.

[12] Araoye, M.O. (2004) Research Methodology with Statistics for Health and Social Sciences. Nathadex Publishers, Ilorin.

[13] Desai, A.M., Mehta, S. and Smith, R.K. (2004) Indoor Smoke from Solid Fuels. Assessing the Environmental Burden of Disease at National and Local Levels. World Health Organization, Geneva.

[14] World Health Organization (2007) Health Effects of Chronic Exposure to Smoke from Biomass Fuel Burning in Rural Areas. Report No. SE/07/118283, Final Report 2007, WHO, Geneva.

[15] Abramson, M., Hensley, M., Saunders, N. and Wlodarczyk, J. (1991) Evaluation of a New Asthma Questionnaire. Journal of Asthma, 28, 129-139. https://doi.org/10.3109/02770909109082737

[16] American Thoracic Society (1969) Standards of Epidemiologic Surveys in Chronic Respiratory Disease. National Tuberculosis and Respiratory Disease Association.

[17] Department of Health Education and Welfare (1971) Proceedings, First National Heart and Lung Institute of Epidemiology Workshop.

[18] Revathi, M., Kutty, K.T. and Annamalai, N. (2012) Pulmonary Function in Rural Women Exposed to Biomass Fuel. Journal of Pulmonology and Respiratory Medicine, 2.

[19] International Society for the Advancement of Kinanthropometry (2001) International Standards for Anthropometric Measurements. The International Society for the Advancement of Kinanthropometry, Adelaide.

[20] Crapo, R.O., Morris, A.H. and Gardner, R.M. (1981) Reference Spirometric Values Using Techniques and Equipments That Meets ATS Recommendations. The 
American Review of Respiratory Disease, 123, 659-664.

[21] Smith-Sivertsen, T., Diaz, E., Pope, D., Lie, R.T., Diaz, A., McCracken, J., et al. (2009) Effect of Reducing Indoor Air Pollution on Women's Respiratory Symptoms and Lung Function: The RESPIRE Randomized Trial, Guatemala. American Journal of Epidemiology, 170, 211-220. https://doi.org/10.1093/aje/kwp100

[22] Levy, L.M., Quanjer, H.P., Booker, R., Cooper, G.B., Holmes, S. and Small, R.I. (2009) Diagnostic Spirometry in Primary Care. Proposed Standards for General Practice Compliant with American Society and European Society Recommendations. Primary Care Respiratory Journal, 18, 130-147. https://doi.org/10.4104/pcrj.2009.00054

[23] Patrick, J.M. and Femi-Pearse, D. (1976) Reference Values for FEV1 and FVC in Nigerian Men and Women: A Graphical Summary. Nigerian Medical Journal, 6, 380-385.

[24] Adeyeye, O.O., Bamisele, R.T., Brodie-Mends, A.T., Adekoya, A.O., Bolarinwa, F.F., Onadeko, B.O., et al. (2012) Five Year Audit of Spirometry at the LASUTH, Ikeja, South-West Nigeria. African Journal of Respiratory Medicine, 8, 15-17.

[25] Jiang, R.T. (2007) Effects of Indoor Particulate Matter Pollution from Biomass Fuels Burning: A Case Study in Six Shenyang Households, Northeastern China in Summer Season. Tropical Resources. Bulletin of the Yale Tropical Resources Institute, 26, 47-54.

[26] Babatunde, R.O., Olorunsanya, E.O. and Adejola, A.D. (2008) Assessment of Rural Household Poverty: Evidence from South-Western Nigeria. American-Eurasian Journal of Agricultural \& Environmental Sciences, 3, 900-905.

[27] Nwude, C.E. (2013) The Politics of Minimum Wage in Nigeria: The Unresolved Issues. Asian Journal of Empirical Research, 3, 477-492.

[28] Salvi, S.S. and Barnes, J.P. (2009) Chronic Obstructive Pulmonary Disease in Non-Smokers. The Lancet, 374, 733-743. https://doi.org/10.1016/S0140-6736(09)61303-9

[29] Fernandes, L. and Mesquita, M.A. (2014) Household Air Pollution Due to Biomass Smoke Exposure and Chronic Obstructive Pulmonary Disease. International Journal of Biomedical and Advance Research, 5, 65-67. https://doi.org/10.7439/ijbar.v5i2.649

[30] Behera, D., Jindal, S.K. and Malhotra, H.S. (1994) Ventilatory Function in Nonsmoking Rural Indian Women Using Different Cooking Fuels. Respiration, 61, 8992. https://doi.org/10.1159/000196313

[31] Dutt, D., Srinivasa, D.K., Rotti, S.B., Sahai, A. and Konar, D. (1996) Effect of Indoor Air Pollution on the Respiratory System of Women Using Different Fuels for Cooking in an Urban Slum of Pondicherry. The National Medical Journal of India, 9, 113-117.

[32] Perez-Padilla, R., Regalado, J., Vedal, S., Pare, P., Chapela, R., Sansores, R., et al. (1996) Exposure to Biomass Smoke and Chronic Airway Disease in Mexican Women. A Case-Control Study. American Journal of Respiratory and Critical Care Medicine, 154, 701-706. https://doi.org/10.1164/ajrccm.154.3.8810608

[33] Pauwels, R.A., Buist, A.S., Calverly, P.M., Jenkins, C.R. and Hurd, S.S. (2001) Global Strategy for the Diagnosis, Management and Prevention of Chronic Pulmonary Disease. NHLBI/WHO Global Initiative for Chronic Obstructive Lung Disease (GOLD) Workshop Summary. American Journal of Respiratory and Critical Care Medicine, 163, 256-276. https://doi.org/10.1164/ajrccm.163.5.2101039

[34] Orozco-Levi, M., Garcia-Aymerich, J., Ramirez-Sarmiento, A., Anto, J.M. and Gea, 
J. (2006) Wood Smoke Exposure and Risk of Chronic Obstructive Pulmonary Disease. European Respiratory Journal, 27, 542-546. https://doi.org/10.1183/09031936.06.00052705

[35] Smith, K., Mehta, S. and Maeusezahl-Feuz, M. (2004) Indoor Air Pollution from Household Use of Solid Fuels. In: Ezzati, M., Lopez, A., Rodgers, A. and Murray, C., Eds., Comparative Quantification of Health Risks. Global and Regional Burden of Disease Attributable to Selected Major Risk Factors, World Health Organization, Geneva, 1435-1493.

[36] Ekici, A., Ekici, M., Kurtipek, E., Akin, A., Arslan, M., Kara, T., et al. (2005) Obstructive Airway Diseases in Women Exposed to Biomass Smoke. Environmental Research, 99, 93-98. https://doi.org/10.1016/j.envres.2005.01.004

[37] Reddy, T.S., Guleria, R., Sinha, S., Sharma, S.K. and Pande, J.N. (2004) Domestic Cooking Fuel and Lung Function in Healthy Non-Smoking Women. Indian Journal of Chest Disease and Allied Science, 46, 85-90.

[38] Akor-Dewu, M.B., Ayo, O.J., Collins, A.R., Mabrouk, M.M., Adelaiye Alexander, B. and Ciroma, L.F. (2012) Comparative Study of Haematological and Cardiorespiratory Parameters in Women Exposed to Biomass or Mixed Fuels. American International Journal of Contemporary Research, 2, 257-263.

[39] Agarwal, A. and Patil, S. (2013) Pulmonary Function Tests in Rural Women Exposed to Biomass Fumes. Indian Journal of Applied Medical Research, 2, 673-678.

[40] Dohoo, C., Guernsey, J.R., Critchley, K. and VanLeeuwen, J. (2012) Pilot Study on the Impact of Biogas as a Fuel Source on Respiratory Health of Women on Rural Kenyan Smallholder Dairy Farms. Journal of Environmental and Public Health, 2012, Article ID: 636298. https://doi.org/10.1155/2012/636298

[41] Eisner, M.D., Anthonisen, N., Coultas, D., Kuenzli, N., Perez-Padilla, R., Postma, D., et al. (2010) An Official American Thoracic Society Public Policy Statement: Novel Risk Factors and the Global Burden of Chronic Obstructive Pulmonary Disease. America Journal of Respiratory and Critical Care Medicine, 182, 693-718. https://doi.org/10.1164/rccm.200811-1757ST

[42] Ling, S. and van Eeden, S. (2009) Particulate Matter Air Pollution Exposure: Role in the Development and Exercabation of Chronic Obstructive Pulmonary Disease. International Journal of Chronic Obstructive Pulmonary Disease, 4, 233-243. https://doi.org/10.2147/COPD.S5098

[43] Guarnieri, M., Diaz, J., handreyi, B., Diaz, A., Pe, D., Mith, K., et al. (2014) Effect of Wood Smoke Exposure on Airway Inflammation in Rural Guatemalam Women. PLOS ONE, 9, e0088455.

[44] Auckland, N.Z. and Munster, F.R.G. (1993) International Syudy of Asthma and Allergies in Childhood (ISAAC) Manual. 2nd Edition. 
Submit or recommend next manuscript to SCIRP and we will provide best service for you:

Accepting pre-submission inquiries through Email, Facebook, LinkedIn, Twitter, etc. A wide selection of journals (inclusive of 9 subjects, more than 200 journals)

Providing 24-hour high-quality service

User-friendly online submission system

Fair and swift peer-review system

Efficient typesetting and proofreading procedure

Display of the result of downloads and visits, as well as the number of cited articles Maximum dissemination of your research work

Submit your manuscript at: http://papersubmission.scirp.org/

Or contact ojpm@scirp.org 